\title{
AMPLIAÇÃO WINNICOTTIANA DA NOÇÃO FREUDIANA DE INCONSCIENTE ${ }^{1}$
}

\author{
Leopoldo Fulgencio
}

Resumo: Nesse artigo pretende-se analisar alguns desenvolvimentos que Winnicott propôs na compreensão do que é o inconsciente, em acréscimo à concepção freudiana do inconsciente reprimido e do recalque originário. Para Freud, o inconsciente diz respeito ao que ele encontrou no tratamento de seus pacientes neuróticos, para os quais o recalque é o mecanismo de defesa por excelência. Procura-se mostrar que Winnicott considera outros aspectos do inconsciente, que têm origem num momento em que o recalque ainda não existe como um mecanismo de defesa; que Winnicott desenvolveu a compreensão do que Freud havia intuído com sua noção de recalque originário, na consideração de acontecimentos, conteúdos e modos de ser que podem ser qualificados como inconscientes, tais como cisões, acontecimentos que foram vividos mas não puderam ser integrados ou experienciados como estando no campo de autonomia do self, bem como a aquisições de modos de ser-estar no mundo.

Palavras-chave: Inconsciente. Recalque. Cisões. Modo de ser. Brincar.

Este artigo tem como objetivo analisar um conjunto de comentários de Winnicott que nos levam a reconhecer que ele se referia ao inconsciente na psicanálise como algo não redutível ao inconsciente reprimido, desenvolvendo e ampliando a proposta de Freud. Para isso, será necessário explicitar as principais características e diferenças entre as concepções de Freud e de Winnicott sobre um tema que sabemos ser o pilar central da teoria e do método de tratamento psicanalítico, ainda que isso não signifique produzir um ensaio exaustivo que aborde o tema em todas

1 Artigo derivado de pesquisa apoiada por Bolsa Produtividade - CNPq. 
as suas nuances. Dada a amplitude e a complexidade desse tema, este artigo propõe delimitar a análise da noção de inconsciente em Freud e das contribuições de Winnicott a este respeito, pensando nos referentes descritivos (por oposição a especulativos) desse conceito, deixando para outro momento a análise de suas características metapsicológicas. ${ }^{2}$

Para Freud $(1900 a)^{3}$, o inconsciente é o psíquico propriamente real. Ele o considera o primeiro xibolete da psicanálise ${ }^{4}$, embora Freud não tenha sido o único a considerar a noção de inconsciente, seja na filosofia ${ }^{5}$ seja na psicologia ${ }^{6}$. Restrito à análise da psicanálise, procura-se explicitar, inicialmente, de que maneira Freud concebeu o que é o inconsciente, selecionando apenas focos e temas desenvolvidos por ele que possam servir para caracterizar as especificidades e as novidades da compreensão que Winnicott tem sobre esse conceito.

Por um lado,é sabido que Freud afirmou ser o inconsciente mais amplo do que haveria sido ali colocado pelo mecanismo do recalque, ou seja, que a noção de um inconsciente reprimido não corresponde à totalidade do que é inconsciente; por outro, porém, Freud não se debruçou de forma extensa sobre a análise do que seria esse outro componente do inconsciente que difere do recalcado. Girard, por exemplo, analisando a obra de Winnicott, considera que o momento inicial em que a criança é cuidada pelo meio ambiente não é registrado em termos de conteúdos psíquicos reprimidos:"nessa unidade inicial criança-ambiente, tudo que diz respeito aos cuidados não é conhecido pela criança e não poderá jamais retor-

2 Alguns autores consideram que há dois corpos teóricos na psicanálise (cf., por exemplo, Fulgencio, 2003, 2008; Grünbaum, 1984): um, no qual há referentes adequados para os conceitos propostos (resistência, transferência, complexo de édipo, repressão etc.), e outro, para os quais não há referente adequado na realidade fenomênica (os conceitos metapsicológicos, stricto sensu, tais como os conceitos de pulsão [força psíquica], libido [energia psíquica] e de aparelho psíquico), todos reconhecidos por Freud como fazendo parte da superestrutura especulativa da psicanálise ou, noutros termos, a sua metapsicologia. Este artigo, que procura analisar quais são os referentes dados por Winnicott ao termo inconsciente, distinguindo referentes factuais de referentes especulativos, se insere numa discussão, em curso no Internationational Journal of Psychoanalysis, sobre a natureza e a função da teorização metapsicológica na obra de Winnicott (cf. Fulgencio, 2007; Girard, 2010).

3 Freud será citado segundo a classificação estabelecida por Tyson e Strachey (1956).

4 Xibolete é uma palavra hebraica que encontramos no Velho Testamento (Livro dos Juízes 12, 6), usada para distinguir os que pertencem ou não a uma determinada tribo: só os que conseguem pronunciar corretamente a palavra pertencem a um determinado grupo. Freud considerou xiboletes da psicanálise a noção de inconsciente (1923b, p. 258), a teoria dos sonhos (1933a, p. 37) e o Complexo de Édipo (1905d, p. 165n). Para uma análise mais detalhada desse tema, veja Fulgencio (2008).

50 próprio Kant diz que há representações claras e obscuras, em função de se darem ou não à consciência, e que estas últimas são mais extensas na composição do psiquismo (Kant, 1798, parágrafo 5). Outros filósofos, como Schopenhauer e Nietzsche (para citar aqui apenas os mais influentes para Freud), também consideram a existência de processos psíquicos inconscientes.

6 Cf. o trabalho de Ellenberger (1970), analisando as propostas de psicoterapias que consideram a noção de inconsciente (Freud, Adler, Jung) como fundamento do psiquismo. 
nar no processo de cura e na transferência; esses acontecimentos não podem ser considerados como fatos que adviriam do desvelamento do recalcamento" (Girard, 2005, p. 20). O próprio Freud (1923b) já teria notado que, nessa situação inicial, o que ocorre não poderia ser explicado com base na noção de recalque, levando-o a supor a existência de um recalque originário. Winnicott $(1960 \mathrm{c} / 1983)^{7}$ reconheceu a direção do pensamento de Freud - "É possível que Freud estivesse tentando prever esses fenômenos quando usou o termo repressão primária [primary repression], mas isto está aberto ao debate" (p. 39) - e desenvolveu outra maneira de descrever e teorizar o que acontece nesse período e o que isso tem a ver com o inconsciente na psicanálise.

Alguns comentadores da obra de Winnicott já se referiram ao fato de que há, nesse autor, uma noção de inconsciente diferente da de Freud. Phillips, por exemplo, sem abordar diretamente esse tema, comenta, en passant, que, no caso de situações em que pessoas passam por uma agonia primitiva (agonia impensável), ocorre uma impossibilidade de realizar a apreensão da situação:"o que foi registrado inconscientemente, na perspectiva de Winnicott, foi uma interrupção, um apagão, na ausência da experiência pessoal do self. Winnicott (1988/1990) iria escrever sobre o inconsciente como, entre ouras coisas, um lugar onde privações foram mantidas" (pp. 21-22). Não se trata de algo que foi reprimido e retirado da consciência, mas da constituição de outro tipo de conteúdo para o inconsciente. Roussillon, distinguindo, em Freud, um inconsciente funcional (ou o pré-consciente) e um inconsciente recalcado, refere-se a um terceiro tipo (passível de ser mais claramente reconhecido com base na obra de Winnicott), um inconsciente dissociado, que se refere ao que não teve lugar, que permanece potencialmente presente sem ter sido realizado, que se refere a algo vivido, mas não simbolizado:

O que foi vivido e não simbolizado, o que assombra as alcovas da psique, vagando, [fica] à procura de uma forma, de uma representação, de uma simples capacidade de presença. Isso existe como inconsciente num sentido de existir enquanto um potencial. Não é a dor do que não foi possível, talvez como mais tardiamente Freud teve a intuição, a culpa ligada ao que não aconteceu. (Roussillon, 1999, p. 18)

Loparic (2006), por sua vez, afirma que Winnicott, além do inconsciente reprimido, se referiu a um inconsciente que tem como referente algo que deveria ter acontecido mas não aconteceu, constituindo um tipo de falha ambiental vivida pelo indivíduo, algo que foi, então, guardado por este, sem uma representação mental.

7 A obra de Winnicott será citada pela classificação estabelecida por Hjulmand (1999, 2007), dado que estará sendo usada na publicação das obras completas de Winnicott, tal como informou Abram (2008). 
As referências indicadas mostram que o tema já foi reconhecido por diversos comentadores da obra de Winnicott, apontando para o reconhecimento desse problema, mas não é objetivo deste artigo analisar as hipóteses propostas por esses comentadores - a de Phillips, que afirma que o inconsciente em Winnicott é um lugar onde as privações foram guardadas, a de Roussillon, que diferencia o inconsciente funcional, recalcado e dissociado, e a de Loparic, que supõe um inconsciente não acontecido -, mas sim, reconhecendo que diversos comentadores da obra de Winnicott têm notado, explicitar quais são as especificidades das concepções de Winnicott, como ele mesmo caracteriza e distingue a sua concepção de inconsciente da de Freud.

Para especificar que tipo de distinção Winnicott fez em relação à noção de inconsciente determinada por Freud procura-se retomar, em linhas gerais, a maneira como este autor explicita a sua noção de inconsciente, tomando o cuidado de diferenciar os aspectos descritivos dos metapsicológicos de suas concepções, para, então, fazer o mesmo com as propostas de Winnicott.

\section{Aspectos descritivos e metapsicológicos da noção de inconsciente para Freud}

Em “Interpretação dos sonhos", Freud (1900a) alude ao inconsciente da psicanálise como sendo diferente do inconsciente dos filósofos e do de Theodor Lipps ${ }^{8}$, querendo com isso dar um referente específico a esse termo. Segundo Freud, em "Interpretação dos sonhos", o inconsciente corresponde, por um lado, a um conjunto de ideias que não são conscientes, tendo sido tornadas inconscientes para evitarem incômodo (ou dor psíquica) à consciência (ao Eu consciente) do indivíduo; por outro lado, corresponde a um sistema ou parte de um aparelho psíquico.

Freud procurou especificar, em diversos momentos de sua obra, qual seria o sentido específico que o termo inconsciente tem para a psicanálise. Sua preocupação, nos principais textos nos quais trata desse tema, é compreender os processos psíquicos inconscientes como algo que tem um funcionamento diferente dos processos que ocorrem na consciência, bem como os distinguir dos processos fisiológicos. No entanto, ainda que os modos de funcionamento dos processos psíquicos conscientes e inconscientes sejam distintos, Freud parece ter tomado o que é encontrável na consciência como a sua referência, de modo que, para ele, a diferença entre os conteúdos da consciência e do inconsciente

8 Para um estudo sobre as diferenças entre Freud e Lipps, veja Lipps (2001), Loparic (2001) e Fulgencio (2008, Parte II, Cap. 2). 
seria, nos processos psíquicos inconscientes, a falta da qualidade de serem conscientes (Freud, 1900a, 1915e).

Em "Notas sobre o inconsciente na psicanálise", Freud (1912g) considera haver três sentidos para o termo inconsciente (o descritivo, o dinâmico e o sistêmico ou metapsicológico). Em primeiro lugar, trata-se de considerar que existem elementos psíquicos que não são dados à consciência, mas que existem enquanto tais, não sendo também redutíveis ao corpo. Esses elementos são representações de conteúdos cognitivos ou representações de estados mentais ou, ainda, representações carregadas de afeto e afetos como representantes de estados mentais. Esse seria o referente e o sentido descritivo do termo inconsciente. Esses elementos psíquicos inconscientes agem entre si, tanto no presente quanto na composição com o passado e o futuro (projetado) numa história de vida. Ao analisar o que são os atos falhos, Freud demonstra que ideias conscientes e inconscientes se determinam entre si produzindo pensamentos e ações, levando-o, então, a caracterizar essa dinâmica como sendo também o sentido e o referente dinâmico do termo inconsciente. Mas isso não era uma novidade na história das ideias, seja na filosofia, seja na ciência. O que Freud considera novo, na sua concepção, corresponde à sua consideração de que o inconsciente é um sistema psíquico, uma das partes que compõem o aparelho psíquico. Freud está ciente de que ele especula, de que a noção de um aparelho psíquico é uma ficção teórica (Freud, 1900a), um conceito de validade apenas heurística, útil para pesquisar e explicar as determinações psíquicas que geram sofrimento e patologia. A um inconsciente assim concebido ele chama de sistêmico ou o inconsciente no seu sentido propriamente metapsicológico (Freud, 1912g). Certamente não há prova empírica do inconsciente metapsicológico, mas tão somente a consideração de que, dessa maneira, temos um ganho de entendimento e de poder clínico. Diz Freud (1915e):"Um ganho de sentido e de coerência é um motivo perfeitamente justificável para ir além dos limites da experiência direta" (pp. 205-206).

Na sua segunda tópica, Freud proporá outra figuração para o aparelho psíquico, com novas instâncias e um novo par de pulsões. Nesse segundo quadro teórico, o termo inconsciente passa a ser usado para qualificar os conteúdos ou partes dessas instâncias. Pode-se afirmar, seguindo os comentários de Laplanche \& Pontalis (1967), que o lugar ocupado pelo Id na segunda tópica é o sistema inconsciente (Ics) da primeira. Sendo assim, podemos afirmar que o sentido metapsicológico ou sistêmico da noção de inconsciente é reafirmada por Freud, ainda que seja necessário notar que essa caracterização metapsicológica não pode ser considerada uma especulação pura, dado que está mesclada com a sua particularização de um inconsciente descritivo e dinâmico.

Freud (1915e) reitera o fato de que tudo o que ele identificou como inconsciente deriva de sua clínica com pacientes neuróticos, nos quais o 
mecanismo básico de defesa contra as angústias, presente e constituinte da própria neurose, é o mecanismo do recalque. Isso faz com que Freud (1923b) considere que a noção de recalque está na base do seu conceito de inconsciente: "Nosso conceito de inconsciente, nós o obtemos, pois, a partir da teoria recalcamento" (pp. 259-260). Ainda que Freud (1915e) diga que o recalcado é apenas uma parte do inconsciente, considera esse mecanismo o modelo de referência para pensar o que é o inconsciente:"o recalcado é para nós o protótipo do inconsciente" (Freud, 1923b, pp. 259260). Nesse sentido, podemos dizer que a grande referência de Freud ao inconsciente diz respeito ao inconsciente recalcado ou reprimido.

Freud (1915d) está ciente que o recalque propriamente dito exige que já esteja dada a distinção entre a consciência e o inconsciente. $O$ recalque não é fundador das instâncias psíquicas, o que o faz especular sobre a existência de uma operação anterior, que realizaria, então, essa fundação, denominada "recalque originário" (p. 191). O agente do recalcamento secundário é certamente o Eu, mas, no caso do recalcamento originário, o Eu ainda não está constituído, o que leva Freud (1915e) a supor outro tipo de ação constituidora do inconsciente, um mecanismo de contrainvestimento com determinadas representações se aglutinando (tal como se fossem atraídas umas pelas outras), compondo um aglomerado que as qualificaria de inconscientes.Também, após 1920, ele abordará um problema parecido, afirmando que o Ego nasce por diferenciação do ld (Freud, 1923b). A caracterização e explicação de como se dá esse contrainvestimento, ou de como o Id vai se diferenciando para constituir o Eu, não foi claramente descrito por Freud.

Apoiado na sua clínica com neuróticos, Freud (1915e) julga que o recalque corresponde ao mecanismo que constitui o conteúdo do inconsciente reprimido; no entanto, ele também reconhece que há pontos obscuros na sua concepção sobre o inconsciente e que, talvez, o estudo das psicoses possa contribuir para esclarecê-los.

Em "Interpretação dos sonhos", Freud se refere aos elementos psíquicos inconscientes como sendo representações, pensamentos, fantasias e desejos. Já em "O ego e o id", diz que foi pela compreensão dos sintomas, dos sonhos e dos atos falhos que ele sentiu-se obrigado a reconhecer a existência de processos psíquicos inconscientes (Freud, 1923b). O que nos leva a afirmar, considerando essas referências, que o inconsciente é composto por um conjunto de representações reprimidas (Freud, 1915e). Freud admite, no entanto, que há mais do que isso no inconsciente, quer, por exemplo, devido às resistências (que não são propriamente dizendo conteúdos recalcados), quer por considerar outros elementos constitucionais do indivíduo, heranças filogenéticas, conteúdos que não são adquiridos na história do indivíduo, dentre os quais se deveria contar as protofantasias.

Ao pensarmos na segunda tópica freudiana, sabemos que tanto o Ego como o SuperEgo têm aspectos inconscientes, mas que no Id há 
apenas conteúdos inconscientes. Se, por um lado, Freud (1923b) afirma que o recalcado se mescla e se funde com o ld, por outro, o recalque corresponde a apenas uma parte do Id, ainda que, nesse ponto, ele pareça chegar ao limite daquilo que deve ser considerado um conteúdo psíquico, refletindo, então, que no Id está presente, como seu fundamento, tudo aquilo que "a biologia e o destino da espécie humana produziram e nos legaram" (p. 280), referindo-se a esses conteúdos, pois, como uma expressão direta das pulsões que impulsionam a vida psíquica.

Assim, para Freud (1915e), até mesmo as pulsões, no inconsciente, só podem ser encontradas na forma de representações. É nesse sentido que Laplanche \& Pontalis (1967, verbete "inconsciente") afirmam que os conteúdos do inconsciente, como um sistema, são representantes das pulsões. O que nos leva a afirmar que, para Freud, o inconsciente, em termos psíquicos, tem representações como seus conteúdos.

Esse sobrevoo na obra de Freud sobre quais são os elementos do inconsciente que não correspondem ao recalcado, remetendo-nos à questão das origens, corresponde apenas a uma indicação que enquadra a análise das referências de Winnicott em outro tipo de inconsciente que difere do inconsciente reprimido, deixando, no entanto, uma série de lacunas para a compreensão desse tema em Freud. Além disso, a preocupação em focar os referentes não especulativos da noção de inconsciente delimitou esse sobrevoo, deixando de lado uma série de formulações de natureza metapsicológica que, noutros contextos, seriam necessárias para compreender a questão do originário e do inconsciente na teoria freudiana.

2. Aspectos descritivos e metapsicológicos da noção de inconsciente feita por Winnicott

Se, por um lado, Winnicott reconhece que Freud deu um grande passo em direção à verdade científica quando propôs a ideia de um Inconsciente Dinâmico, por outro, abandonou a concepção de um inconsciente como um conceito metapsicológico e considerou que a proposta de Freud, referindo-se ao inconsciente reprimido, era insuficiente para compreender uma série de fenômenos que ele pôde apreender com sua teoria do desenvolvimento afetivo e com a sua clínica tratando de pacientes psicóticos e de bebês.

Também para Winnicott (1989vl/1994) a repressão está na gênese da neurose, caracterizando-a da seguinte maneira:

Repressão é o nome dado à perda, pela consciência em uma pessoa mais ou menos saudável, de um conjunto de sentimentos, memórias e ideias tendo como 
causa a dor intolerável que ocorre quando são trazidos à consciência o amor e o ódio coincidentes, bem como o temor à retaliação. (Winnicott, 1988/1990, p. 159)

Assim, o neurótico é aquele ser humano que, tendo chegado à integração como uma pessoa inteira, ${ }^{9}$ vive conflitos na administração da sua vida instintual no relacionamento com outras pessoas num cenário edípico e envolto em questões identificatórias (Winnicott, 1958m/2000). Winnicott $(1945 \mathrm{~h} / 1997,1963 \mathrm{c} / 1983)$ diz que há, pois, nos neuróticos, uma forma particular de inconsciente adequadamente denominável inconsciente reprimido.

Winnicott (1987d/1994) afirma que a própria existência de um inconsciente, em termos mais gerais, só tem sentido quando alguma consciência pode existir: "não sendo conscientes, os bebês não podem ser inconscientes" (p. 94). Temos, pois, que considerar: 1) que, no início, para o bebê, não há lugar algum para qualquer referência a algo que poderia ser considerado com um inconsciente; 2) que o inconsciente reprimido só poderá ter existência quando existir um amadurecimento no qual a distinção Eu-nãoEu tiver sido alcançada, quando a diferenciação entre mundo externo e mundo interno é possível de ser experienciada, ou seja, quando há uma integração na qual pode haver um Eu que pode colocar em funcionamento o mecanismo do recalque (Winnicott, 1984i/1999, 1989vl/1994).

No início do processo de desenvolvimento afetivo, a realidade psíquica do ser humano se confunde com o próprio corpo. Diz Winnicott (1968d/1994): "Para o bebê não existe um consciente e um inconsciente na área que pretendo examinar. O que há, ali, é um complexo anatômico e fisiológico, e, junto a isso, um potencial para o desenvolvimento de uma personalidade humana" (p. 79). O corpo não é apenas a biologia, mas sim esta última acrescentada de sentidos dados ao que ocorre com o corpo, sentidos que são dados pelo que Winnicott denominou elaboração imaginativa das funções corporais. ${ }^{10}$

Só um longo desenvolvimento, levando o indivíduo à sua unidade como sujeito psicológico, tornará possível o surgimento do mecanismo de recalque e do inconsciente reprimido. Antes desse momento, em que o indivíduo está integrado num EU, possível agente da repressão, ocorre um

9 Chegado ao estágio do EU SOU e seguido, na fase do concernimento (ou posição depressiva), integrando no seu self tanto a sua instintualidade (o que, antes desse momento, era vivida como sendo algo exterior ao self) quanto seus impulsos amorosos e destrutivos, reconhecendo o outro também como pessoa inteira.

10 A elaboração imaginativa (cf. Winnicott, 1965vf/2001, 1987b/1990 - p. 77, carta a Victor Smirnoff de 19/11/1958, 1988/1990) tem, no início, um significado muito simples, para tornar-se cada vez mais complexa, participando desde a aquisição de uma noção de tempo e de espaço, e do longo processo de personalização (iniciado com 0 alojamento da psique no corpo e continuado em direção à conquista do status de pessoa inteira), até funções altamente elaboradas, como sonhar, desejar e fantasiar (compreendendo, agora, esse fantasiar no seu sentido mais clássico, relativa a uma construção imaginária do indivíduo e das relações do indivíduo com base em suas representações mais ou menos deformadas, mais ou menos deslocadas). 
conjunto significativo de integrações do indivíduo, tais como a constituição de uma noção de temporalidade, de espacialidade, a união entre aquilo que acontece com o corpo e os sentidos dados a esses acontecimentos (caracterizando o que Winnicott denominou alojamento da psique no corpo), que dizem respeito a modos de ser-estar no mundo, de como o ser pode seguir em sua continuidade, apoiado e sustentado pelo ambiente. Esses modos de ser são integrações e conquistas do processo de desenvolvimento afetivo que não são dados conscientes e que, nesse sentido amplo, mereceriam ser qualificados como inconscientes, mas certamente não correspondem ao inconsciente reprimido descrito por Freud.

Winnicott (1955d/2000,1989vl/1994) dirá que há dois grandes polos da psicopatologia a serem considerados: o da neurose e o da psicose. Entre eles há um conjunto de possibilidades intermediárias, dentre as quais ele colocará todos os tipos de depressão, além de incluir uma série de sintomas relativos aos transtornos psicossomáticos e a atitude antissocial. Não é a classificação psicopatológica que quero colocar em foco, mas a compreensão da distinção dos processos psíquicos inconscientes em cada um desses extremos.

Enquanto o inconsciente reprimido estaria, necessariamente, ligado ao neurótico, no caso dos psicóticos, Winnicott (1963c/1983) percebe outro tipo de processo de defesa contra a angústia que decorre das falhas de sustentação ambiental num momento em que o indivíduo ainda não tem um Eu integrado ou, noutros termos, outro tipo de organização ou de conteúdo inconsciente:"A repressão faz parte da neurose, assim como o splitting da personalidade faz parte da psicose" (p. 197).

Há de se considerar duas situações: nos casos patológicos, aquelas pessoas "cujos estágios mais iniciais de desenvolvimento são incompletos e esta qualidade domina o quadro clínico" (Winnicott, 1989vl/1994, p. 53); noutra, quando há saúde, o processo de amadurecimento ainda não chegou ao estágio em que há uma pessoa inteira (com um mundo interno e um mundo externo diferenciados) que se relaciona com os outros também tomados e reconhecidos como pessoas inteiras.

Pacientes psicóticos são pessoas não integradas e a cisão é a característica dominante. Nesse caso, não é possível considerar um inconsciente reprimido, pois este exige condições que ainda não foram alcançadas: "não é possível a uma personalidade cindida ter um inconsciente reprimido, por não haver lugar para ele ficar" (Winnicott, 1964h/1994, p. 370), ou ainda,"a cisão toma o lugar do inconsciente reprimido do psiconeurótico" (1968c/1994, p. 152).

O tratamento dos pacientes cuja personalidade está cindida não corresponde a trazer um inconsciente reprimido à tona, mas a outro tipo de trabalho que pressupõe lidar com a cisão do paciente, buscando lhe dar as condições ambientais para amadurecer (integrar-se) em direção à constituição da unidade chamada EU. 
No artigo "Medo do colapso", de 1974, Winnicott afirma que alguns pacientes temem viver um tipo de loucura que na verdade já ocorreu, um colapso já vivido, mas que não pode ser experimentado. Esse fato ocorrido, que o paciente guarda consigo, corresponde a um trauma tornado inconsciente, que determina a vida do paciente, ainda que esse algo inconsciente não possa ser considerado inconsciente pelo recalque. Procurando especificar que tipo de inconsciente é esse, Winnicott (1974/1994) explicita:

Trata-se de um fato que se carrega consigo, escondido no inconsciente. Este último aqui, não é exatamente o inconsciente reprimido da psiconeurose, nem, tampouco, o inconsciente da formulação freudiana da parte da psique que se acha muito próxima do funcionamento neurofisiológico. (p.73)

Algo foi vivido, guardado na memória, certamente não propriamente como um conteúdo reprimido nem como algo que possa ser, no sentido estrito do termo, lembrado, tampouco como a representação de algo, mas, mesmo assim, permanecerá como parte da psique daquela pessoa. Winnicott (1989vl/1994) diz que algo foi vivido, mas não foi experienciado, ocorrendo um tipo de morte fenomenal. ${ }^{11}$

Não obstante, o trauma ocorreu e ficou registrado. Esse fato, guardado no inconsciente, não pode ser uma representação que o EU faria de tal ou tal acontecimento, dado que esse EU ainda não está lá: "Neste contexto especial, o inconsciente quer dizer que a integração do ego não é capaz de abranger algo. $O$ ego é imaturo demais para reunir todos os fenômenos dentro da área da onipotência pessoal" (Winnicott, 1974/1994, p. 73). À angústia aí vivida é denominada por Winnicott "agonia impensável" [unthinkable anxiety] (cf. em Winnicott, 1989vh/1994, p. 99), ${ }^{12}$ dado que há um EU integrado que pode pensar ou mesmo ter essa experiência. Assim, um dos aspectos desses elementos inconscientes guardados - ou congelados pelo indivíduo, como explicita Winnicott (1955d/2000) - corresponde a algo vivido, mas que não pode ser experienciado, como uma morte fenomenal (1974/1994), que permaneceria como um dado inconsciente à espera de melhores condições para ser retomado e integrado na área do self (1960c/1983).

Outro aspecto desse inconsciente que permanece no indivíduo como um tipo de acontecimento a ser integrado no campo do self diz respeito a momentos em que "nada aconteceu quando algo poderia proveitosamente ter acontecido" (1974/1994, p. 75), um tipo de necessida-

11 Para fornecer um conteúdo mais intuitivo a essa expressão de Winnicott (1974/1994, p. 75), ou seja, a tal fato vivido mas não experienciado, Winnicott o compara com o que ocorre com o bulbo e a flor que dele emana quando amadurece: 0 perfume da flor à qual o bulbo dará origem está lá, mas nenhuma dissecação ou análise poderia encontrá-lo, só o desenvolvimento dessa situação o fará presente (1989vl/1994, pp. 99-100).

12 Ele descreve estas agonias impensáveis como tendo algumas poucas variedades: "1. quebrar em pedaços; 2. cair para sempre; 3. não ter conexão alguma com o corpo; 4. carecer de orientação" $(1965$ n/1983, p. 57) 
de e/ou expectativa que era importante para a continuidade de ser do indivíduo, mas que, por falha ambiental, não ocorreu. Talvez seja o caso de supor, como já foi sugerido por Loparic, (1999), um inconsciente nãoacontecido. ${ }^{13}$

Muitos outros adjetivos poderiam qualificar esse tipo de inconsciente (cindido, não sustentado no tempo, nãorepresentacional etc.), especialmente ligando-o a acontecimentos patológicos, a falhas ambientais, à impossibilidade de integração de acontecimentos vividos em função da imaturidade do indivíduo, a nãoacontecidos, a elementos cindidos no indivíduo. Esse conjunto de adjetivos nos levaria a considerar, então, no caso da patologia, um inconsciente impensável ou agonias impensáveis, um inconsciente congelado, enfim, um inconsciente que difere do inconsciente reprimido tal como Freud propôs. O que importa aqui é a caracterização do tipo de dado que se torna inconsciente, mostrando que estamos num campo em que não é uma representação (seja a representação de coisa, seja a representação de palavra, ou melhor, "representação por meio de palavras [conceitos]") que é tornada inconsciente, mas outro tipo de dado psíquico.

Caberia perguntar que tipo de inconsciente fica presente nos casos saudáveis em que não há ainda integração do self para que o mecanismo de repressão possa ocorrer, mas em que há uma série de vivências que, na maturidade posterior, não estão presentes na consciência e nem por isso podem ser ditas reprimidas. Segundo Winnicott (1965j/1983), o inconsciente que nunca pode se tornar consciente não é análogo ao inconsciente reprimido, mas se trata de um inconsciente não redutível a um conjunto de representações, que é gerado num momento em que o bebê é imaturo para ter representações mentais.

Winnicott (1989xf/1994), coerentemente, passa a denominá-lo inconsciente primário (p. 343). Já comentamos o fato de que, no período pré-natal e logo após o nascimento, a vida psíquica se confunde com a somática (1968d/1994); mas não se trata apenas de um corpo que recebe sentidos, cujas experiências são catalogadas, organizadas, separadas e relacionadas (1965n/1983) - um corpo biológico -, mas do corpo que está sendo "colorido" semanticamente pela elaboração imaginativa das funções corporais.

Com a continuidade do processo de amadurecimento, nessa fase inicial, que Winnicott denomina fase da dependência absoluta e da dependência relativa ${ }^{14}$, temos um conjunto amplo de integrações que não

13 Essa maneira de enunciar ou interpretar o que propôs Winnicott, considerando que há um inconsciente não acontecido, traz problemas lógicos e epistemológicos. No entanto, o problema aqui não é aprofundar e procurar resolver uma aparente contradição ou um paradoxo, mas sim considerar que há, em Winnicott, um inconsciente que não corresponde ao inconsciente reprimido de Freud.

14 Veja em Winnicott (1965r/1983), uma apresentação da teoria do desenvolvimento afetivo em termos do tipo de dependência que o indivíduo vive em relação ao ambiente. 
são, de forma alguma, dados filogenéticos, mas aquisições que ocorrem porque há uma sustentação ambiental das necessidades de ser, a saber: a temporalização, a espacialização, o alojamento da psique no corpo, o desenvolvimento da capacidade de ter fé, o primeiro reconhecimento da dependência, a criação-encontro dos objetos e fenômenos transicionais, a constituição de um modo de ser-estar no mundo marcado pela distinção Eu-NãoEu, a conquista da capacidade de brincar etc. Todas essas aquisições ou conquistas não podem ser tidas como representações, nem como afetos; elas são, mais propriamente, modos de ser e modos de ser no mundo.

Podemos comentar alguns aspectos que caracterizam determinados modos de ser relacionados com o mundo e com o outro - tais como a capacidade de ter "fé em..." e a capacidade de brincar - como característicos de um inconsciente primário ou constitucional, buscando fornecer descrições mais objetivas sobre esse inconsciente. Poder-se-ia objetar que esses aspectos associados às conquistas mais primitivas (temporalização, espacialização, personalização, capacidade de ter fé etc.), bem como às agonias impensáveis, são de natureza cronológica e afetiva díspares da capacidade de brincar e, portanto, não deveriam ser colocadas, juntas, como fazendo parte desse inconsciente primário. No entanto, se pensamos nessas conquistas como integrações do indivíduo, levando-o à possibilidade de ser e afirmar-se como um self, essas conquistas podem ser elementos e processos psíquicos inconscientes que, por sua vez, não são elementos ou processos (dinâmicas e conflitos) recalcados, ainda que, no desenvolvimento do indivíduo que chega à possibilidade de usar o recalque como mecanismo de defesa, este pode gerar conflitos inconscientes recalcados que dificultam ou mesmo impedem esses modos de ser no mundo. Farei a seguir alguns comentários para explicitar o que acabo de afirmar.

Um ambiente suficientemente bom, que, mesmo sendo imperfeito, entende e atende às necessidades da criança, ou seja, fornece-lhe os objetos de que tem necessidade, acaba por gerar, na criança, um tipo de fé e esperança: considerando uma adaptação ambiental que não desaponta a criança nesse momento, ela pode constituir em si mesma a possibilidade de ter "fé em...", isto é, de ter a esperança e a expectativa de que há no mundo o que ela precisa, de que ela pode encontrar no mundo o que está de acordo com as suas necessidades (cf. Winnicott, 1963d, 1986k). Trata-se, na verdade, da confiança, dada pela adaptação ambiental, de que a necessidade (de ser) será atendida, de que a linha da vida não será quebrada. É a capacidade de acreditar ou ter fé, e não exatamente fé nisso ou naquilo, ou seja, fé de que é possível SER, pois o mundo que torna possível esse ser é um mundo que não a desaponta.

$\mathrm{Na}$ continuidade desse processo, quando há saúde, surgem os objetos e fenômenos transicionais, os quais não são também, por sua vez, apenas um conjunto de projeções e introjeções, mas modos de ser-es- 
tar e de se relacionar consigo e com o mundo. Mais importante do que os objetos transicionais em si (um pano, um ursinho etc.), é a maneira como o indivíduo se relaciona com eles (Winnicott, 1953c/1975, p. 15). Esse modo de relação corresponde também à aquisição da capacidade e possibilidade de brincar, como um aspecto universal da natureza humana. Ao caracterizar o que é a ação de brincar e o que deriva dela, Winnicott (1971r/1975) dirá que ela é uma forma de comunicação que leva ao encontro de si mesmo e do outro, e que "a psicanálise foi desenvolvida como forma altamente especializada do brincar, a serviço da comunicação consigo mesmo e com os outros" (1968i/1975, p.63).

A incapacidade de brincar é uma imaturidade que deve ser tratada pela sustentação ambiental, exercendo o que Winnicott caracterizou como ilusão de contato, que ocorre na vivência dos fenômenos transicionais. Quando encontramos um paciente que não sabe brincar, que não amadureceu a este ponto, cabe ao analista levá-lo a essa conquista; isso ocorre em função da sustentação ambiental que o analista pode fazer, que corresponde a uma experiência de comunicação e de contato verdadeiros. Nesse sentido, o trabalho do analista não é acessar o inconsciente reprimido, mas tornar possível um modo de ser e experienciá-lo com o paciente..$^{15} \mathrm{~A}$ brincadeira, como modo de ser-estar, corresponde, pois, a um modo de ser inconsciente, partilhável ou compartilhável entre paciente e analista, que deve ser desenvolvido; mais ainda, deve ser desenvolvido como uma capacidade que funciona inconscientemente. Se a brincadeira for planejada conscientemente, ela perde sua característica essencial, que é a sua espontaneidade criativa.

Os conteúdos desse inconsciente primário não são, propriamente, conteúdos psíquicos, não são ideias nem representações de afetos ou de estados mentais. Na saúde, são modos de ser e estar pelos quais se pode operar no mundo (1986h/1994); na patologia, correspondem a cisões, e mesmo não acontecidos, à espera de condições para serem integrados no campo do self. Não são, pois, conteúdos reprimidos ou objeto de mecanismos de defesa (relativos aos conteúdos da mente), mesmo que possam ser objeto de outros mecanismos de defesa (cisão, não integração corpo e psique, congelamento quando da falha ambiental etc.). Não obstante, com o amadurecimento e integrações do indivíduo e a conquista de modos de ser que incluem a possibilidade de representar, bem como a de recalcar elementos e conflitos que dizem respeito à administração da vida instintual nas relações interpessoais, ou seja, com a conquista da capacidade de representar e de recalcar, as representações e os afetos 
também estarão associados a esse inconsciente, amalgamando-se com os conteúdos de um inconsciente reprimido.

O inconsciente primário, na saúde ou na patologia, será o alicerce do desenvolvimento afetivo. Na saúde, esse alicerce dará as bases para que a neurose possa ser edificada e, mesmo assim, não são propriamente conteúdos nem vivências reprimidas, nem mesmo retidas em função da angústia. Um inconsciente não exatamente representável, ou ainda, passível de ser facilmente colocado em palavras ou numa forma discursiva (talvez nas artes isso seja possível), mas sempre real e presente em todos os modos de ser-estar no mundo, infantis ou adultos.

No caso dos neuróticos, não há dúvida que caberá ao analista tratar do inconsciente reprimido, dado que essas determinações inconscientes tornam a vida do paciente constrangida. Ao referir-se aos psicóticos, no entanto, Winnicott (1988/1990) afirma que os problemas desses pacientes dizem respeito à luta para alcançarem a vida, ou seja, à possibilidade de se integrarem para, então, terem problemas propriamente relacionais: "um tratamento bem-sucedido de um psicótico permite que o paciente comece a viver e comece a experimentar as dificuldades inerentes à vida" (p. 100). Para chegar à vida, trata-se, então, de integrar-se no tempo, no espaço, personalizar-se em termos de realizar uma integração (alojamento) da psique no corpo, ter fé no mundo (ter esperança de que é possível encontrar no mundo aquilo de que se necessita para ser), poder criar e encontrar o mundo (o que significa ter conquistado a capacidade de brincar), e da conquista da unidade do sujeito psicológico em termos da integração EU SOU e, depois, da chegada ao status de pessoa inteira. Essas integrações não se dão em função do mecanismo de recalque, mas sim pela sustentação ambiental.

Nesse sentido, é possível compreender um pouco mais por que a maior parte do trabalho analítico ocorre em função de modos de ser inconscientes, isso sem que esqueçamos a importância e a presença das determinações psíquicas que advêm do inconsciente reprimido, que precisa ser interpretado na transferência.

Nenhuma das referências de Winnicott ao inconsciente são relativas a instâncias psíquicas, a figurações de partes de um fictício aparelho psíquico. Não são ficções teóricas, ficções heurísticas, como as que encontramos em Freud para figurar, tornar visível, o que ocorre na vida psíquica. O próprio Green notou que Winnicott (2005) não usa a noção de aparelho psíquico; o que torna possível afirmar, apoiado também no desenvolvimento que fiz até agora, que Winnicott não se refere ao inconsciente como um sistema psíquico, ou seja, em termos metapsicológicos. Tanto a noção de inconsciente reprimido como a de um inconsciente primário são conceitos que se referem a modos de funcionamento pessoais reconhecíveis objetivamente na experiência factual. Não se trata, para Winnicott, de uma figuração ou analogia, mas 
de um inconsciente relativo a conteúdos e vivências da história pessoal e relacional de um ser humano, seja nos casos em que há representações reprimidas, seja nos casos em que esse inconsciente é composto de elementos não propriamente representáveis.

Pode-se afirmar que Winnicott, apoiado na compreensão que Freud forneceu sobre o que é a vida psíquica inconsciente, desenvolveu e ampliou o entendimento sobre o que são as determinações psíquicas inconscientes, para além da dimensão do inconsciente reprimido. Seu modo de teorizar afastou-se do uso de ficções teóricas, do uso de analogias e figurações especulativas, diferenciando-o, epistemologicamente falando, de outros autores pós-Freud que aprofundaram, desenvolveram e mesmo reformularam a metapsicologia freudiana propondo outras superestruturas especulativas. Não se trata, a meu ver, de uma questão teórica, ou filosófico-epistemológica, mas sim de, consideradas essas proposições de Winnicott, verificar que desdobramentos clínicos advêm de sua compreensão do que é o inconsciente e suas determinações.

\title{
Winnicottian enlargement of the Freudian concept of unconscious
}

\begin{abstract}
The purpose of this article is to examine some developments proposed by Winnicott in the understanding of what the unconscious is, an addition to the Freudian conception of repressed unconscious and that of primary repression. For Freud, this unconscious is related to what he discovered in the treatment of his neurotic patients who find in the repression a defence mechanism par excellence. It will be shown that Winnicott considers other aspects of the unconscious which originate when repression does not exist as a defence mechanism; that Winnicott developed the understanding of what Freud had conceived with his notion of primary repression, by considering events, contents and modes of being which may be characterized as unconscious such as splitting, events which were lived but couldn't be integrated or experienced in the field of autonomy of the self, as well as some acquisitions of modes of being in the world.
\end{abstract}

Keywords: Unconscious. Repression. Splitting. Mode of being. Playing. 


\section{Élargissement winnicottien du concept freudien de l'inconscient}

Résumé: Dans cet article, il y a eu l'intention d'analyser quelques développements proposés par Winnicott dans la compréhension de ce qu'est l'inconscient, venant s'ajouter à la conception freudienne de l'inconscient réprimé et de refoulement originaire. Pour Freud cet inconscient se rapporte à ce qu'il a trouvé dans le traitement de ses patients névrotiques, pour lesquels le refoulement est le mécanisme de défense par excellence. On montrera que Winnicott considère d'autres aspects de l'inconscient ayant leur origine à un moment où le refoulement n'existe pas encore comme mécanisme de défense; que Winnicott a développé la compréhension de ce que Freud avait eu comme intuition avec sa notion de refoulement originaire, en considérant des événements, des contenus et des modes d'êtres pouvant être qualifiés comme inconscients, tels que les clivages, les événements vécus mais pas intégrés ou expérimentés dans le champ d'autonomie du moi, ainsi que quelques acquisitions de modes d'être dans le monde.

Mots-clés: Inconscient. Refoulement. Clivage. Mode d'être. Jouer.

\section{Ampliación winnicottiana del concepto freudiano de inconsciente}

Resumen: En este artículo, se ha tenido la intención de analizar algunos desarrollos que Winnicott propuso en la comprensión de lo que es el inconsciente, añadiendo a la concepción freudiana del inconsciente reprimido y de la represión originaria. Para Freud ese inconsciente se refiere a lo que él encontró en el tratamiento de sus pacientes neuróticos, para los cuales la represión es el mecanismo de defensa por excelencia. Se demostrará que Winnicott considera otros aspectos del inconsciente, que se originan a partir de un momento en que la represión no existe todavía como un mecanismo de defensa; que Winnicott desarrolló la comprensión de lo que Freud intuyó con su noción de represión originaria, en la consideración de los hechos, contenidos y modos de ser que pueden ser calificados como inconscientes, como por ejemplo escisiones, acontecimientos vividos pero que no pudieron ser integrados o experimentados en el campo de la autonomía del yo, así como algunas adquisiciones de modos de ser-estar en el mundo.

Palabras claves: Inconsciente. Represión. Escisión. Modo de ser. Jugar. 


\section{Referências}

Abram, J. (2008). Donald Woods Winnicott (1896-1971): A brief introduction. The International Journal of Psychoanalysis, 89(6), 1189-1217.

Ellenberger, H. F. (1970). The discovery of the unconscious. The history and evolution of dynamic psychiatry. New York, NY: Basic Books.

Freud, S. (1900a). L'intrepretation des rêves. In S. Freud, Oeuvres complètes (OCF.P) (Vol. 4). Paris, France: PUF.

Freud, S. (1905d). Trois essais sur la thèorie sexuelle. In S. Freud, Oeuvres complètes (OCF.P) (Vol. 6). Paris, France: PUF.

Freud, S. (1912g). Note sur l'inconscient en psychanalyse. In S. Freud, Oeuvres complètes (OCF.P) (Vol. 11). Paris, France: PUF.

Freud, S. (1915d). Le refoulement. In S. Freud, Oeuvres complètes (OCF.P) (Vol. 13). Paris, France: PUF.

Freud, S. (1915e). L'inconscient. In S. Freud, Oeuvres complètes (OCF.P) (Vol. 13). Paris, France: PUF.

Freud, S. (1923b). Le moi et le ça. In S. Freud, Oeuvres complètes (OCF.P) (Vol. 16). Paris, France: PUF.

Freud, S. (1933a). Nouvelles suite des leçons d'introdution à la psychanalyse. In S. Freud, Oeuvres complètes (OCF.P) (Vol. 19). Paris, France: PUF.

Fulgencio, L. (2003). As especulações metapsicológicas de Freud. Revista de Filosofia e Psicanálise Natureza Humana, 5(1), 127-164.

Fulgencio, L. (2007). Winnicott's rejection of the basic concepts of Freud's metapsychology. International Journal of Psychoanalysis, 88(2), 443-461.

Fulgencio, L. (2008). O método especulativo em Freud. São Paulo, SP: EDUC.

Girard, M. (2005). L'accueil en pratique institutionnelle. Immaturité, schizophrénies et bruissements du monde. Paris, France: Champ Social.

Girard, M. (2010). Winnicott's foundation for the basic concepts of Freud's metapsychology? The International Journal of Psychoanalysis, 91(2), 305-324.

Green, A. (2005). Winnicott at the start of the third millennium. In L. Caldwell (Ed.), 
Sex and sexuality: Winnicottian perspectives (Winnicott Studies Monograph Series). London, UK: Karnac Books.

Grünbaum, A. (1984). The foundations of psychoanalysis. Berkeley, CA: University of California Press.

Hjulmand, K. (1999). Lista completa das publicações de D. W. Winnicott. Revista de Filosofia e Psicanálise Natureza Humana, 1(2), 459-517.

Hjulmand, K. (2007). D. W. Winnicott: Bibliography: Chronological and alphabetical lists. In J. Abram, The language of Winnicott: A dictionary of Winnicott's use of words (2 ed., pp. 363-435). London, UK: Karnac.

Kant, I. (1798). Antropologie du point de vue pragmatique. Paris, France: Vrin.

Laplanche, J., \& Pontalis, J.-B. (1967). Vocabulaire de psychanalyse. Paris, France: PUF.

Lipps, T. (2001). O conceito de inconsciente na psicologia. Revista de Filosofia e Psicanálsie Natureza Humana, 3(1), 335-356.

Loparic, Z. (1999). É dizível o inconsciente? Revista de Filosofia e Psicanálise Natureza Humana, 1(2), 323-385.

Loparic, Z. (2001). Theodor Lipps: uma fonte esquecida do paradigma freudiano. Revista de Filosofia e Psicanálise Natureza Humana, 3(1), 315-331.

Loparic, Z. (2006). De Freud a Winnicott: aspectos de uma mudança paradigmática. Revista de Filosofia e Psicanálise Natureza Humana, 8(Especial 1), 21-47.

Phillips, A. (1988). Winnicott. London, UK: Fontana Press.

Roussillon, R. (1999). Introduction à nouvelle édition de Le paradoxe de Winnicott. Actualité de Winnicott. In A. Clancier \& J. Kalmanovitch, Le paradoxe de Winnicott. De la naissance à la creation (pp. 9-26). Paris, France: In Press.

Tyson, A., \& Strachey, J. (1956). A chronological hand-list of Freud's works. International Journal of Psychoanalysis, 37(1), 19-33.

Winnicott, D. W. (1975). O brincar: uma exposição teórica. In O brincar \& a realidade (pp. 59-77). Rio de Janeiro, RJ: Imago. (Trabalho original publicado em 1968i)

Winnicott, D. W. (1975). O brincar: a atividade criativa e a busca do Eu (Self). In O brincar \& a Realidade (pp. 79-93). Rio de Janeiro, RJ: Imago. (Trabalho original publicado em 1971r) 
Winnicott, D. W. (1975). Objetos transicionais e fenômenos transicionais. In O brincar \& a realidade (pp. 13-44). Rio de Janeiro, RJ: Imago. (Trabalho original publicado em 1953c)

Winnicott, D. W. (1983). Comunicação e falta de comunicação levando ao estudo de certos opostos. In O ambiente e os processos de maturação (pp. 163-174). Porto Alegre, RS: Artmed. (Trabalho original publicado em 1965j)

Winnicott, D. W. (1983). Da dependência à independência no desenvolvimento do indivíduo. In O ambiente e os processos de maturação (pp. 79-87). Porto Alegre, RS: Artmed. (Trabalho original publicado em 1965r)

Winnicott, D. W. (1983). Os doentes mentais na prática clínica. In $O$ ambiente e os processos de maturação (pp. 196-206). Porto Alegre, RS: Artmed. (Trabalho original publicado em 1963c)

Winnicott, D. W. (1983). A integração do ego no desenvolvimento da criança. In $O$ ambiente e os processos de maturação (pp. 55-61). Porto Alegre, RS: Artmed. (Trabalho original publicado em 1965n)

Winnicott, D. W. (1983). Moral e educação. In O ambiente e os processos de maturação (pp. 88-98). Porto Alegre, RS: Artmed. (Trabalho original publicado em 1963d)

Winnicott, D. W. (1983). Teoria do relacionamento paterno-infantil. In O ambiente e os processos de maturação (pp. 38-54). Porto Alegre, RS: Artmed. (Trabalho original publicado em 1960c)

Winnicott, D. W. (1990). O gesto espontâneo. São Paulo, SP: Martins Fontes. (Trabalho original publicado em 1987b)

Winnicott, D. W. (1990). Natureza humana. Rio de Janeiro, RJ: Imago. (Trabalho original publicado em 1988)

Winnicott, D. W. (1994). O brincar e a cultura. In Explorações psicanalíticas: D. W. Winnicott (pp. 160-162). Porto Alegre, RS: Artes Médicas. (Trabalho original publicado em 1989vh)

Winnicott, D. W. (1994). A comunicação entre o bebê e a mãe e entre a mãe e o bebê: convergências e divergências. In Os bebês e suas mães (pp. 79-92). São Paulo, SP: Martins Fontes. (Trabalho original publicado em 1968d)

Winnicott, D. W. (1994). O conceito de regressão clínica comparado com o de organização defensiva. In Explorações psicanalíticas: D. W. Winnicott (pp. 151-156). Porto Alegre, RS: Artes Médicas. (Trabalho original publicado em 1968c) 
Winnicott, D. W. (1994). O destino do objeto transicional. In Explorações psicanalíticas: D. W. Winnicott (pp. 44-48). Porto Alegre, RS: Artes Médicas. (Trabalho original publicado em 1989i)

Winnicott, D. W. (1994). O medo do colapso. In Explorações psicanalíticas: D. W. Winnicott (pp. 70-76). Porto Alegre, RS: Artes Médicas. (Trabalho original publicado em 1974)

Winnicott, D. W. (1994). Notas Preliminares para "A comunicação entre o bebê e a mãe e entre a mãe e o bebê: convergências e divergências" (após Fonte dos capítulos). In Os bebês e suas mães (pp. 94-96). São Paulo, SP: Martins Fontes. (Trabalho original publicado em 1987d)

Winnicott, D. W. (1994). Primórdios de uma formulação de uma apreciação e crítica de enunciado kleiniano da inveja. (Parte II do cap. 53 - Melanie Klein: sobre o seu conceito de inveja). In Explorações psicanalíticas: D. W. Winnicott (pp. 340-347). Porto Alegre, RS: Artes Médicas. (Trabalho original publicado em 1989xf)

Winnicott, D. W. (1994). Psiconeurose na infância. In Explorações psicanalíticas: $D$. W. Winnicott (pp. 53-58). Porto Alegre, RS: Artes Médicas. (Trabalho original publicado em $1989 \mathrm{vl})$

Winnicott, D. W. (1994). Resenha de Memories, Dreams, Reflections, de C. J. Jung. In Explorações psicanalíticas: D. W. Winnicott (pp. 365-372). Porto Alegre, RS: Artes Médicas. (Trabalho original publicado em 1964h)

Winnicott, D. W. (1997). Para um estudo objetivo da natureza humana. In Pensando sobre crianças (pp. 31-37). Porto Alegre, RS: Artes Médicas. (Trabalho original publicado em 1945h)

Winnicott, D. W. (1999). Psicanálise e ciência: amigas ou parentes? In Tudo começa em casa (pp. XIII-XVIII). São Paulo, SP: Martins Fontes. (Trabalho original publicado em 1986k)

Winnicott, D. W. (1999). Variedades de psicoterapia. In Privação e delinquência (pp. 263-273). São Paulo, SP: Martins Fontes. (Trabalho original publicado em 1984i)

Winnicott, D. W. (1999). Vivendo de modo criativo. In Tudo começa em casa (pp. 2339). São Paulo, SP: Martins Fontes. (Trabalho original publicado em 1986h)

Winnicott, D. W. (2000). Aspectos clínicos e metapsicológicos da regressão no contexto psicanalítico. In Da pediatria à psicanálise: obras escolhidas (pp. 374-392). Rio de Janeiro, RJ: Imago. (Trabalho original publicado em 1955d) 
Winnicott, D. W. (2000). Pediatria e neurose da infância. In Da pediatria à psicanálise: obras escolhidas (pp. 417-423). Rio de Janeiro, RJ: Imago. (Trabalho original publicado em 1958m)

Winnicott, D. W. (2001). O relacionamento inicial da mãe com o filho. In A família e o desenvolvimento individual (pp. 21-28). São Paulo, SP: Martins Fontes. (Trabalho original publicado em 1965vf) 
Leopoldo Fulgencio, docente do Programa de Pós-Graduação em Psicologia da Pontifícia Universidade Católica de Campinas. Endereço para correspondência: Rua Marcos Azevedo, n. 93, Pinheiros, São Paulo, SP, Brasil. CEP:05428-050. Endereço eletrônico: leopoldo.fulgencio@gmail.com

Recebido: $19 / 09 / 2012$

Aceito: 26/02/2013 